\section{Et billede på dagliglivet: 100-året for Småtrykssamlingens oprettelse - 1902-2002}

AfAnne-Marie Smith, afdelingsbibliotekar på Det Kongelige Bibliotek

"Denne Afdeling giver et mærkeligt og værdifuldt Billede af Tidens sociale og økonomiske Liv, således som det former sig gennem disse ellers så oversete Smaating, som Beretninger, Regnskaber, Programmer, Cirkulærer o.s.v."

S ådan skriver overbibliotekar H.O. Lange $\mathrm{i}$ "Aarsberetning om det store kongelige Bibliotheks Virksomhed i Finansaaret 1902-1903" - ord, der er dækkende den dag i dag for den nuværende Småtrykssamling.

Baggrunden er, at d. 2. maj 1902 vedtog Landstinget "Lov om offentlige Bibliotekers Ret til Frieksemplarer af Tryksager m.m”. Denne lov var en udvidelse af bogtrykkernes afleveringspligt i forhold til den tidligere lov og betød først og fremmest, at flere såkaldte "småtryk" nu skulle afleveres. I samme årsberetning skriver H.O. Lange, at antal modtagne småtryk er steget fra 3837 til 14493, og at "Ordningen af Smaatrykket ... er fremmet af al Kraft". Til sammenligning modtog Småtrykssamlingen i 2001 199045 småtryk.

Overbibliotekaren slutter sin beretning om Småtryksafdelingen således: "Ordningsarbejdet må udføres i Sommermaanederne, naar Temperaturen i Biblioteks- lokalerne tillader længere Ophold derude, saa de store Masser, der ere indkomne ved Nytaarsafleveringen, kunne først blive ordnede i Løbet af indeværende Sommer, hvis Arbejdet da overhovedet kan magtes med det nuværende Personale."

\section{Småtryk: Stor, men ikke støvet}

iden oprettelsen af afdelingen i 1902

er der sket store ændringer, dels i

$\checkmark$ materialets mængde, dels i behandlingen af det. Bl.a. er alle småtrykstidsskrifter og årspublikationer efter 1960 blevet registreret i Det Kongelige Biblioteks onlinekatalog REX. Hele samlingen er opstillet efter en særlig systematik i knap 100 emnegrupper, som stadig er brugbare, selvom nogle af gruppernes navne måske kan lyde gammeldags. Det hedder således stadigvæk Adspredelser, Gensidig Støtte, Lægekunst og Rejseliv. Grupperne er.så rummelige, at det er muligt at placere tryksager fra $2002 \mathrm{i}$ dem - og takket være reglerne for placering af den enkelte tryksag, kan man finde den igen.

ormålet med denne artikel er ikke at
komme ind på håndteringen af
tryksagerne med alle de hovedregler, undtagelser, finurligheder og krinkelkroge, der er, men at være appetitvækker til samlingen og til udstillingen Alle Tiders Tryk, der vises i Galleriet i Den Sorte Diamant fra den 21. juni. Selvom oprettelsen af en selvstændig Småtryksafdeling først skete i 1902, findes der småtryk helt tilbage til 1600-tallet. I alt er der i samlingen ca. 6 millioner tryk, som fylder 5 kilometer.

S amlingen befinder sig i den del af Det Kongelige Bibliotek, som blev bygget af arkitekt Holm, og som ligger i

Bibliotekshaven over for Christiansborg. 


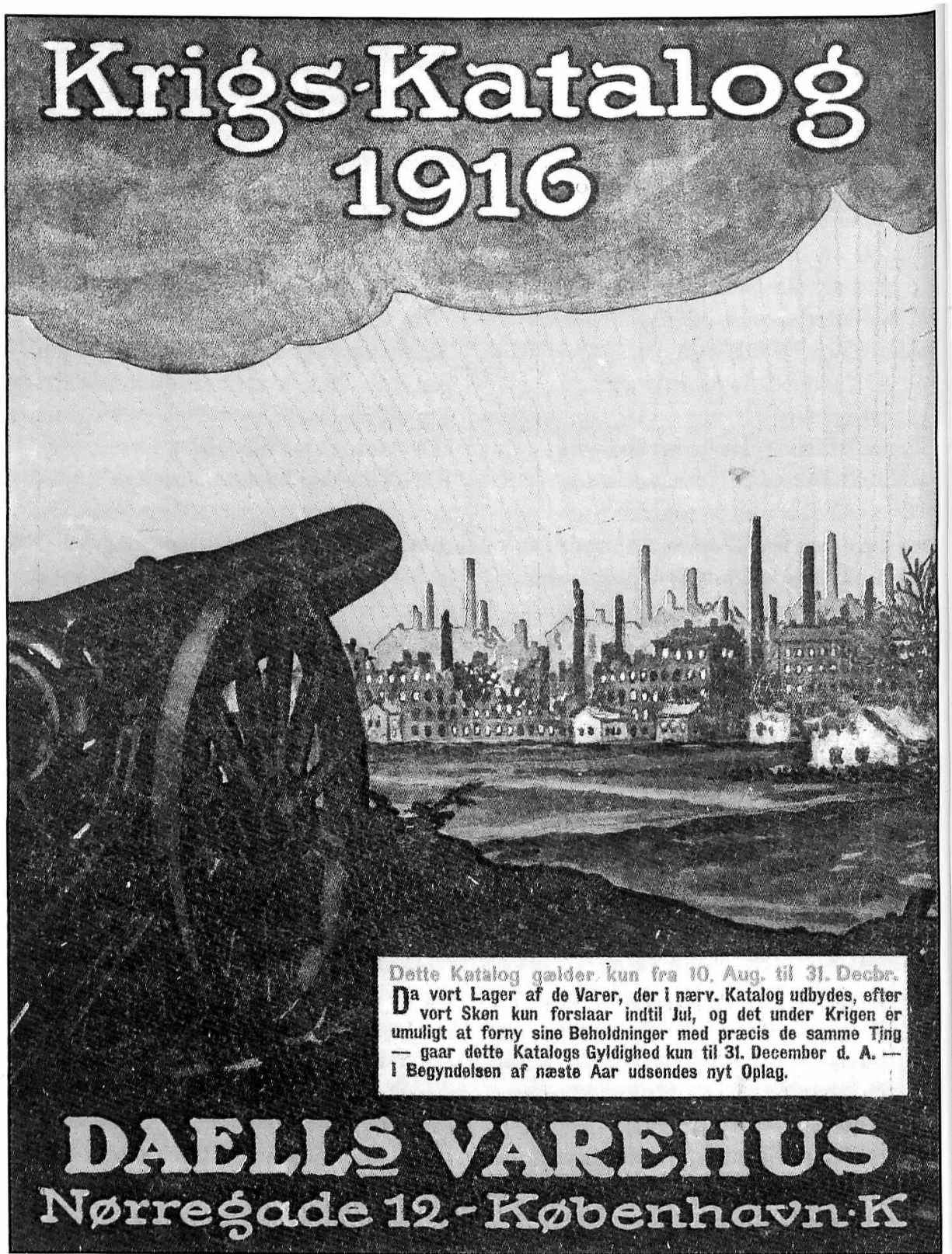

Daells Varehus. Krigs-Katalog 1916. Udkom under 1. verdenskrig og har en sønderskudt by $p a ̊$ forsiden. Teksten gør opmerksom $p \ddot{a}$, at varelageret er knapt, og at "det under Krigen er umuligt at forny sine Beholdninger med precis de samme Ting". (Foto: Det Kongelige Bibliotek). 
Bygningen blev indviet i 1906 og blev indrettet med jernriste gennem alle etagerne af hensyn til lyset og opvarmningen. Det har dog den ulempe, som Holm selv bemærker, nemlig at: "Ristegulve tillader Støvet at sænke sig ned gjennem alle Etager ...". Men materialet ligger godt beskyttet $\mathrm{i}$ bindekapsler i magasinerne i nærheden af Læsesal Vest i Den Sorte Diamant, hvor det skal benyttes af lånerne.

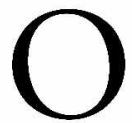
rdet "småtryk" betyder ikke, at tryksagerne nødvendigvis er små, det kan være alt lige fra etbladsløbesedler til tykke telefonbøger. Betegnelsen går snarere på, at det er anonyme tryk, dvs. uden egentlig forfatter. Man kunne også kalde småtryk for "korporationstrylk", nemlig firmaers, foreningers og institutioners aktuelle interne tryk. Typiske tryk er vedtægter, årsberetninger og regnskaber, personaleblade, firmablade, skoleblade og prislister. Desuden findes i samlingen kataloger (for såvel kunst som landbrugsmaskiner), programmer for teatre, koncerter og film og meget andet.

\section{Småtryk fra vugge til grav}

$\mathrm{H}$ vis man ville gennemgå et menneskes liv fra fødsel til grav, kunne man gøre det ved hjælp af Småtrykssamlingens emnegrupper: Fødsel (Lagekunst), enlig mor (Filantropi, Forsorg), børnehave og skole (Skolevesen), bryllup, (Kirkeliv), uddannelse (Højere Loreanstalter), arbejde (Faglige foreninger), erhvervsliv (Aktieselskaber, Handel, Havebrug, Industri, Landvesen, Penge), offentlige myndigheder (Kommunalvasen, Politi, Retspleje, Skattevesen, Statsstyre), fritid og fornøjelser ( Film, Idrat, Musik, Oplysning, Selskabelige foreninger, Teater) og sundhed og sygdom (Afhold, Gensidig støtte, Lagekunst). Alle aspekter af tilværelsen kan belyses i form af tryksager.

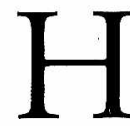
er er nogle eksempler fra de forskellige grupper. Tager man Rejseliv, finder man her mindre turisthåndbøger, hoteller, restauranter, funktionærer $\mathrm{i}$ hotelbranchen, turistforeninger, rejsebureauer osv. Bag denne opremsning gemmer sig f.eks. en folder fra Oversøisk Passagerbureau, der i 1932 tilbyder Forårsrejse til Grækenland - Tyrkiet - Tunis - Italien med "Monte Rosa", der beskrives som "et såkaldt "Enhedsskib", d.v.s. at det kun fører een Klasse, og alle Passagererne har lige Adgang til Salonerne, Læseværelserne, de brede Promenade- og Soldæk og i øvrigt overalt paa Skibet". Turen varer 26 dage og kan med III. klasses jernbane til Genua og hjem fra Venedig og køjeplads i "Skibets store luftige Fælleskahytter" gøres for $850 \mathrm{kr}$. Det dækker alle rejseudgifter, undtagen drikkevarer. I Rejseliv står også turisthåndbogen "Ferie i Danmark". Her finder man i årgang 1929 følgende beskrivelse fra Nymindegab Kro: "Aaben hele Aaret. Pension omfatter: Morgenmaaltid Kl. 8-11: Koldt Bord, Kaffe eller The. Frokost KI. 1: Varm Ret og koldt Bord. Middag Kl. 7: 2 Retter og Dessert. Strandbade gratis. Rig Anledning til Strandjagt. Klaver forefindes". Pensionsprisen er 6,50 kr. om dagen. Ved at læse i turisthåndbogen fremgår det, at det ikke er en selvfølge, at strandbade er gratis, et badehotel forlanger f.eks. 35 øre pr. strandbad. Om Nærum Sommerpensionat står der: "Morgenmaaltid 8-9. Frokost Kl. 12. Middag Kl. 5 1/2, 2 Retter og Dessert. The Kl. 9 Aften. Elektr. Lys. W.C. Stor Have. Egen Skovlaage til Dyrehaven. Egnen er smuk, og her er landligt og roligt...." Pensionspris fra $5 \mathrm{kr}$. Specielt må egen skovlåge være attraktivt! 


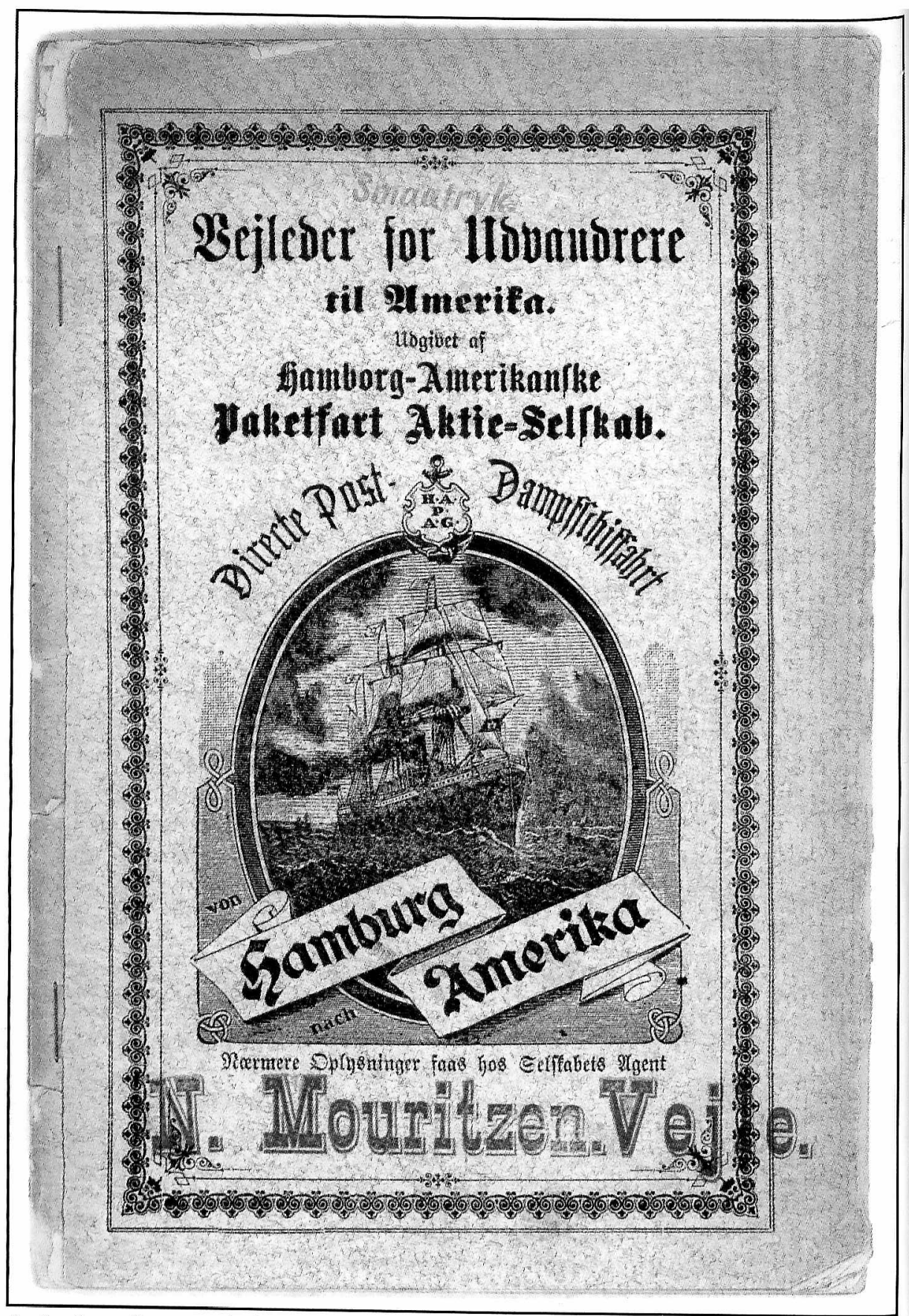

Småtrykssamlingen er alsidig i sin dakning afrejselivet. (Foto: Det Kongelige Bibliotek). 
$\mathrm{V}$ ll man se andre typer tryksager om det at rejse i videste forstand udvandring, skibsrejser, parlører,

DSB-udflugter osv. - må man foretage afstikkere til emnegrupper som Jernbaner eller Søfart. I en "Vejleder for Udvandrere til Amerika", udgivet af Hamborg-Amerikanske Paketfart Aktie-Selskab i 1889, er der fra s.28-39 en lille parlør med de vigtigste ord og sætninger "særlig bestemt for Udvandrere". Her kan man under "Samtale paa Skib og Jærnbane" læse følgende spørgsmål "Vil De ikke sige mig hvor Dampskibet State of Georgia ligger?" Udtalen angives som: "Pliis tell mi wher tde Stiim Schip Stæt ov Jorjia leis?" Eller under "At spørge om Arbejde": "Kan ju emploi a seørvant gørl? Ei hev bin i e dæri for tuu jiirs, ænd sørved von jiir as Tjæmbermæd ænd no hov tu du plæn kukking." Eller "Ei vaant to no if ju kan juus mi in jur faktori. Ei æm villing tu mæk meiself generally jusful, ænd wi niid not spik about wædjes bifaar ju sii what Ei kan du". Og en sidste prøve: "Hev ju vork for e jørnimann blaksmith? Ei hev vork'd in e maschinsjop in Denmark ænd kann røn æn enjein". De sidste sætninger bør man læse højt for at få det fulde udbytte af dem.

\section{Det Kongelige Bibliotek anno 1793}

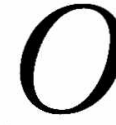
plysning indeholder blandt meget andet folkeuniversiteter, biblioteksvæsen, læseselskaber, forsamlingshuse og de upolitiske ungdomsforeninger. I en af bindekapslerne ligger der et reglement, et såkaldt Rescript, for Det Kongelige Bibliotek fra 1793, det år, hvor biblioteket for første gang åbnede sine døre for offentligheden. I det kan man læse, at der er åbent alle søgnedage fra klokken 10 til 12 om formiddagen, at det forbydes "aldeles at tage bøgerne på egen hånd udaf reolerne", og at lånetiden er 14 dage. I dag kan man se det nyeste reglement for benyttelse på bibliotekets hjemmeside, og der er åbne hylder på bibliotekets betjeningssteder.

I Havebrug står der et lille indbundet bind med beretninger 1883-90 fra Det Kongelige Danske Haveselskab, omhandlende "Uddeling af Præmier til Husmænd for havemæssig Dyrkning af deres Jordlodder". I hver beretning er der en fortegnelse over "Dhrr., der have ledet Bedømmelsen og Præmieringen i de forskjellige Amter". Dhrr. er enkelte gartnere, men ellers er det navne som godsejer Lemvigh, godsforvalter Repholtz , justitsråd Finsen, grev Petersdorff, etatsråd Tesdorpf, kammerherre, baron Berner-SchildenHolstén, og pastor Thygesen, der for de enkelte amter har haft med præmieringen at gøre. Beretningerne indeholder en angivelse af de enkelte jordlodders størrelse, en nøje gennemgang af, hvilke afgrøder der dyrkes, og en omhyggelig redegørelse for indtægter og udgifter. F.eks. står der i M.C. Melhedes regnskab for året 1883 under indtægter: "Geden er fodret med Gulerødder; Indtægt af Mælk $40 \mathrm{Kr}$." og som fodnote til udgifterne er tilføjet: "NB. Hestegødning er ikke ført til Udgift, da dette er velvilligt Vederlag for Haveprodukter, som ikke er ført til Indtægt". I det hele taget udmærker beretningerne sig ved deres detailrigdom: "Havelodden dyrkes af Ansøgeren personlig og Lugningen udføres ved hjælp af hans Børn" (Arrestforvarer Jens Hansen, Herning). "Ansøgeren er Banevogter og maa som saadan være paa Banen fra om Morgenen Kl. 6 til om Aftenen Kl. 6 og Arbejdet er altsaa udført i Fritiden" (Niels Peter Jacobsen, Hesselholdt). "Manden er en dygtig og flittig Murer, saa at det egentlig er hans Kone, der passer Haven. Men det er en sand Fornøjelse at se med hvilken Dygtig- 
hed hun haandterer Spaden og de andre Haveredskaber ..." (Husmand Rasmus Tobiesen, Skjærup). "I Stormfloden 1872 skylledes hans Hus bort, og Højvande gaar ofte op og skjuler Jorden, hvorfor han i den nederste Del af Haven har anlagt Aspargesbede, der ikke tager Skade af Havvandet" (Husmand Per Hansen, Køge). "Dette Havebrug drives af en ihærdig gammel Mand, der trodser Alder og den ugunstige Sommer efter bedste Evne" (Husejer og skrædder Claus Pedersen, Vaarbymark pr. Vemmeløv). "Arbejdet i Haven udføres udelukkende af Manden i hans Fritid med Hjælp af Konen og 6 ukonfirmerede Børn. Da Familien er saa stor, kan der i Regelen ikke sælges noget af Havens Udbytte, men det er en god Hjælp til de mange Munde" (Smed David Peter Hermansen, Arden).

L agekunst har fra gammel tid været en broget blanding. Her står sundhedsvedtægter, hospitaler, institutioner for døve og blinde, rekonvalescenthjem, kursteder og sygehjem, medicinalfabrikker, apoteker, læger, jordemødre etc. Endvidere badeanstalter, naturlæger, vegetarer, fodlæger, veterinærvæsen, rotteudryddelse og mange andre emner, som har hørt med til tidernes opfattelse af sundhed og sygdom.

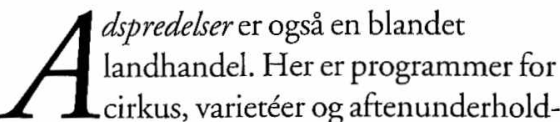
ning, kabaretkunstnere, oplæsere, visesangere, basarer, menagerier, artister, tankelæsere og tryllekunstnere. Her findes f.eks. programmet for et lysbilled-foredrag med titlen "Paa Vinterfangst med Lofotfiskerne" ved forfatterinden Estrid Ott, programmer for Kunstnerkabaretten "Edderkoppen", illustreret af Storm P., og for optræden af skuespilleren Kai Børgesen, København, som næppe mange kender i dag. Han optræder bl.a. med "Toget gaar (humoristisk Stepning)" og "Harmonikaspil med Fløjtning (uden Instrument)", præsenteret af forretningsfører K. Glad.

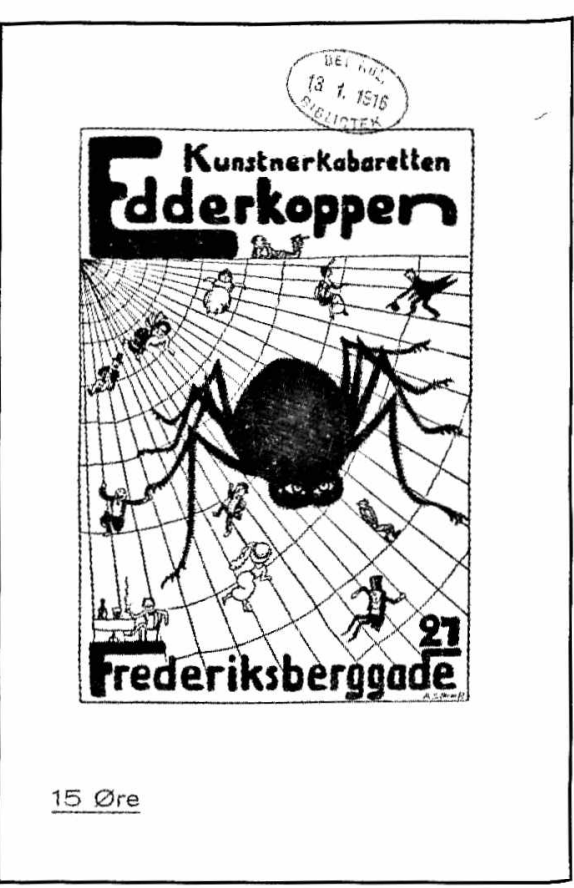

Robert Storm Petersens karakteristiske streg $p a$ Kunstnerkabaretten Edderkoppens program fra 1916. (Foto: Det Kongelige Bibliotek).

\section{Forenings-Danmark}

t Danmark er et blomstrende
foreningsland ses tydeligt i samlin-
gen. Spredt ud i grupperne findes foreninger for snart sagt alt: "De Højes Klub", "Afholdssangforeningen Urania (bl. Kor)" (der som formål har "ved smukke 4stemmige Sange at forskaffe alle en behagelig Underholdning samt efter Evne altid at virke og agitere for Afholdssagens Fremme"). Der er foreninger for pianostemmere, 


\section{Foreningen \\ Fattiǵe Borns Fodbeklædning}

i Kobenhavn.

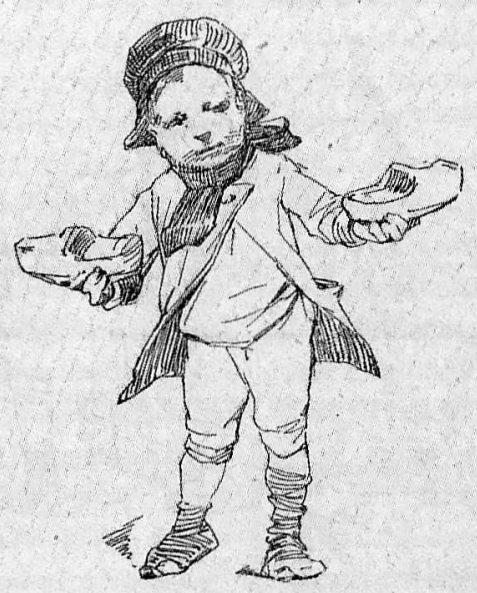

Med sholos Fod $i$ Vintersjap Er ikbe rart at tredel

Ver derfor: ikbe allfor knag,

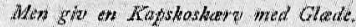

I1. Aarsberetning $1899-1900$.

Kobenhavn.

Ladvig Jorgezsons Bogtrykkeri, Amagertorv 10

1900.

Foreningens navn er nesten blevet et begreb. Her er forsiden af beretningen for 1899-1900 med det lille vers: "Med skolos Fod $i$ Vintersjap/Er ikke rart at trade!/Ver derfor ikke altfor knap/Men giv en Kapskoskarv med Glade."

Dyrehavsmalere, for producenter af "dansk Ost af Roquefort-typen", solbadeforeninger, kaninavlerforeninger og meget mere. Her er "Foreningen til forvildede unge Pigers Frelse", og foreningen "Fattige Børns Fodbeklædning" har vitterlig eksisteret. Er der foreninger, er der også medlemsblade. Man glæder sig, når Dansk Brætsejler Organisation kalder medlemsbladet for "Board med blæsten", eller Rørcentret på Teknologisk Institut udgiver "Kloaktuelt". Der er navne som "De Røde Heste" (personaleblad for Combus i Horsens), "Udslip" (Miljø- og Levnedsmid- 
delkontrollen Fyn), "Kratluskeren" (Ålborg Orienteringsklub), "Åreknuden" (medlemsblad for en roklub) eller "Spejderhagl" (en titel, som dækker KFUM-spejdernes

Silkeborggruppe). Der har været udvist stor idérigdom, som når stormagasinet Magasin udgiver et personaleblad ved navn "Bikuben", Sparekassen Bikuben et blad med titlen "Bistanden", og "Bilaget" udgives af en biavlerforening og ikke, som man måske kunne tro, af en forening af revisorer.

\section{Småtryksperiodika i stor skala}

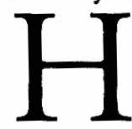

vis man vil danne sig et overblik over småtryksperiodika udkommet efter 1960 kan man studere

Dansk Periodicafortegnelse II, som udkom 2001. Med sine knap 19000 indførsler på årlige publikationer som beretninger, regnskaber og medlemsfortegnelser og tidsskrifter som kirkeblade, idrætsblade, personaleblade, kundeblade og skoleblade er den en væsentlig kilde for alle, der interesserer sig for kultur- og danmarkshistorie i det 20. og 21. århundrede.

\section{Verden i} følge Småtryk - før og nu et foregående har mest handlet om de ældre tryksager, som jo ofte udøver en særlig fortryllelse, men man kunne også have skrevet om kommunernes aktuelle budgetter og regnskaber, skolebladene, overenskomsterne, de nyeste prislister eller museernes aktuelle udstillingskataloger. Det spændende ved samlingen er at den er levende, at materialet hele tiden ændrer sig i takt med udviklingen i samfundet.
Overgangen fra landbrugsland til industrisamfund kan ganske enkelt ses $i$ mængden af tryksager. F. eks har man i Landvesen haft rækker af stambøger: Stambog over Connemara ponyer, Stambog for Dansk Varmblod, over heste af fjordracen eller Dansk Jersey-stambog. Det billede er helt ændret. Bankfusioner betyder ændringer i Penge. Kendte firmaer forsvinder, og nye opstår, det ser man i Aktieselskaber. Nogle grupper sygner hen, andre liver op. Filantropi afløses af Forsorg. Gruppen Mejerivasen, hvor alle de lokale mejerier en gang var repræsenteret med vedtægter og regnskaber - hylde op og hylde ned - består nu nærmest kun af ét mejeri. Tilgangen til samlingen af filmprogrammer er næsten stoppet, fordi de ikke udkommer længere, og mådeholdsforeninger i Afhold er bestemt heller ikke noget, man ofte støder på i vore dage.

Nu er der "grønne regnskaber", "holistiske regnskaber", "etiske regnskaber", børsprospekter og publikationer om miljøog græsrodsbevægelser. Selv i Bøger til udfyldning, som bl.a. indeholder (ubeskrevne) venindebøger, er der sket en udvikling. Nu er der også "Mine Drengevenner", hvor rubrikkerne om yndlingsfarve, livret og bedste bog er afløst af "Første gang vi kyssede", "Hvorfor gik det i stykker" og "Hvordan klarede jeg savnet".

Kort sagt, som man plejer at sige i Småtrykssamlingen: "Småtryk skildrer ikke livet, det er selve livet!"

Yderligere oplysninger om Småtrykssamlingen kan fås via <www.kb.dk> 